\title{
THE USE OF AERIAL PHOTOGRAPHS IN FOREST SURVEYING
}

\author{
By \\ G. S. Andrews and L. G. Trorey \\ Forest Surveys Division \\ British Columbia Forest Service \\ PART I. \\ PHOTOGRAMMETRIC METHODS \\ By \\ L. G. TROREY

\section{INTRODUCTION}

Aerial photographs taken by the Royal Canadian Air Force have been used in connection with the work of the Forest Surveys Division, British Columbia Forest Service, during the last two years and aerial type maps have been made by this Division covering an area of 530,000 acres. This paper embodies some results of the experience gained in the construction of these maps.

Only sufficient of the iconometric theory is dealt with to enable a person, previously unfamiliar with the subject, to have an intelligent understanding of a vertical aerial photograph. The remainder of the paper deals with the practical details of the procedure developed in the Forest Surveys Division. The system described requires no complicated or expensive apparatus, only a pantagraph being used in addition to a simple mirror stereoscope.

Articles 1 to 4 inclusive, of section $I$, were adapted from an address given by Mr. G. S. Andrews to the Forestry Discussion Club, Victoria, in April, 1932. Most of the references given in the bibliography, and in particular Hotine's "Surveying from Air Photographs," have been freely consulted, both in the preparation of the paper and in the work it describes.

\section{CONTENTS}

\section{PART ONE}

I. Aerial Surveying

1. Aerial methods in general

2. Obliques and verticals

3. Uses of Aerial Photographs

4. Limitations and advantages of air methods.

5. Aerial methods in forest surveys 
II. Fundamental Properties of Vertical Photographs

1. Scale

2. Properties of $p$.

3. Recapitulation

4. Optical and geometric considerations

5. Tilt

III. The Principal Point Plot

1. Overlap

2. Crab

3. The radial line method

4. Adjustment

5. Scale of minor control plot

IV. Simple Stereocomparison

1. Stereoscopic impression

2. The use of the stereoscope

3. Floating marks

4. Transference of points

5. Points on water

6. Transference by eye

V. Simple Mapping from Sterenscopic Parrs

1. Preparation of the prints

2. Transference of detail to the plot

3. Topography

VI. THE MAP

1. Ground control

2. Reduction of the minor control plot to the scale of the base map

3. Transference of reduced minor control plots to the base map

4. Special difficulties

VII. Practice

1. The index map

2. The filing system

3. Detailed order of operations

4. Explanation of operations

5. Organization

6. Accuracy

7. Costs

BIBLIOGRAPHY

FIGURES 


\section{THE USE OF AERIAL PHOTOGRAPHS IN FOREST SURVEYING}

(Figures in brackets refer to publications

listed in bibliography at end of article).

\section{Aerial Surveying}

\section{Aerial Methods in General.}

Aerial methods in surveying may be referred to as direct and indirect. The direct method constitutes flying over an area with a trained observer who sketches the information desired and discernable directly on to a largescale base map during the flight. It is beyond the scope of this paper to go into the details of direct mapping from the air, sufficient to point out that the method is inexact, requires a base map of high accuracy and detail, skilled observers, and is subject to omissions. Fairly extensive projects of this type have been executed by the Ontario Forest Branch (2). Much early military reconnaissance was carried out in this manner.

Indirect methods entail photographing from an aeroplane the entire area to be covered, and the later compilation of maps or mosaics in the office. This method has the advantage that, once the photographs are in hand, any recognizable detail can at any time be plotted from them since they are on file as a permanent record. Let us say the primary object of an air survey is to prepare a topographic map; assume that this is done in the usual way and the final maps published; at a later time the occasion may arise where a forest reconnaissance of the same area is required. By the photographic method it is not necessary to go out and fly the area again, but only to refer to the photographs on file, and to plot from them the forest types. Similarly any other details not included in the original map compilation may be at any later time taken off. Furthermore, discrepancies in compiling a map may be checked and rectified by reference to the photos on file without any costly return to the area.

\section{Obliques $\& 3$ Verticals.}

Aerial photographs may be of two kinds, obliques and verticals. The two types are compared below:

Oblique Photographs

1. Optical axis at oblique angle to horizontal-i.e. camera aimed at a slant.

2. Flying elevation usually $5,000^{\prime}$.
Vertical Photographs

1. Optical axis perpendicular to horizontal plain of ground, i.e., camera aimed vertically downward.

2. Flying elevation $15,000^{\prime}$ to $20,000^{\prime}$ or less depending on the map scale desired. 
3. Flights 3 to 6 miles wide.

4. Applicable only to flat terrain.

5. Accuracy limited to scale $1^{\prime \prime}=4$ miles or $1: 253440$.

6. Stereoscopy not generally applicable.

7. Panorama.

8. Cost of photography half that of vertical.
3. Flights 2 miles wide (ordinarily).

4. Applicable to flat or rough terrain.

5. Almost any desired precision may be obtained, depending on the fly. ing elevation, ground control and method of plotting.

6. May be used stereoscopically, contouring.

7. Mosaics.

8. Cost of photography twice that of obliques.

3. Uses of aerial photographs.

Maps and data from aerial photography are, in the present stage of development, most applicable to the following projects:-

1. Topographic surveys-similar to the photo-topographic surveys pur, sued by the Provincial and Federal Governments.

2. Forest reconnaissance and ecological surveys.

3. Land classification-demarcation of cultivated lands, grazing areas, natural meadows, drainage, improvements, etc.

4. Railway and road location surveys-including logging railroads.

5. Working plan surveys in connection with logging operations, river improvement for log driving, mill construction, dam and water-storage, or hydro-electric power development.

6. Highway and bridge location surveys.

7. Geological surveys.

8. Coast-line surveys.

9. Municipal and town planning surveys.

10. Military reconnaissance.

In connection with location surveys of various kinds a great advantage of the aerial method is that the whole survey may be made without the knowledge of property owners or others along the proposed route. This makes it possible to lay out a detailed right-of-way, and to quietly check up ownership in the Land Titles Office, without causing the speculative boom which often follows the presence of a survey party in the field. Thus delay in construction resulting from inflated land values and unnecessary litigation may often be avoided.

With reference to land classification and agriculture, aerial photographs show exactly the truth about conditions on the ground. This is of far reaching value in land administration and taxation, litigation, etc. Lawsuits arising 
from alleged misrepresentation of facts pertaining to the areas cleared, in crop, swamp and water, or timber, etc., in a parcel of land, may be quickly settled where the area has been covered by vertical photographs. Homestead applications may be intelligently and quickly disposed of by the authorities when they can refer to aerial photographs of the actual land in question. A glance shows whether the particular quarter is forest land, swamp, steep sidehill, benchland, river bottom, meadow, barren, or rock slide, and the relative proportions of each of these on the quarter.

The use of aerial photographic data in geological and soil surveys is somewhat more involved. The advantages of a detailed physiographic map showing drainage, land forms in contour, and the disposition of rock outcrops, are obtainable from aerial photographs. However, where it is necessary to use the various types of vegetative cover as criteria of the value of the underlying formations or deposits, detailed studies usually have to be made in correlation. It is probable that in B.C. generally this correlation cannot be followed to a rational conclusion due to the continual interruption of vegetative succession cycles and climaces by forest fires. However, there is practically nothing known of the subject here. In Northern Rhodesia remarkable success has been achieved in the correlation of cover types with the underlying soil and geological formation. (4).

4. Limitations and advantages of air methods.

The disadvantages of aerial methods are largely due to the still primitive stage of organization and to the lack of facilities for universal civil aviation. Among the most important of these are:

1. High cost of photography per unit area when applied to small areas.

2. Necessity to await favourable weather conditions. (This, however, is not peculiar to air photography).

3. The difficulty in measuring tree-height, age and cull factor from the photographs.

Some advantages of air methods follow.

1. Wealth, exactness and permanence of the information:

Every part of the area can be inspected and checked up as desired. Nothing is missed, even to the smallest creek or sub-type. (With photographs taken at 12,000 feet by a camera with a 12 -inch focus lens, eight feet by eight feet is about the limiting size of an object readily discernable. A tree count would in general require a somewhat larger scale).

A set of aerial photos covering an area comprises a permanent record of the ground, on file, available for reference at any time. True, vegetative cover does change through growth, fires, and invasion of denuded areas. However, wide-spread changes will not occur in 50-year periods. Further, the ground itself is the same to all intents and purposes for generations. The 
information is absolutely unbiased-entirely free from human judgment which enters into the manuscript data of all ground reconnaissance methods. With aerial photographs it is possible to give a very fair cruise and estimate of timber on every individual section, or quarter section, even when no examination plot lies within its boundaries. To carry it further, every individual acre could be written up.

2. Speed at which large areas of difficult country may be covered with reduction to a minimum of expensive and arduous ground work.

The speed of aerial surveys may be illustrated by the following typical example-area 450 square miles-cruise for a pulpmill project, including river-driving plans, dam location, water and log storage mill-site, etc. Country was accessible by steamer and there was a 12 to 20 -mile drive. Topography rough ridges to $4,000^{\prime}$ and separating deep valleys-

Air-photography took-1 week.

Ground party took-2 weeks.

Office work, map compiling, mosaic and report submitted to owners in 5 weeks-total cost $\$ 11.00$ per square mile, $\$ 5,000.00$. An adjoining area of 350 square miles of similar country took 8 months to complete by a ground party. (This cost figure covers the particular example given and cannot be taken to have general application).

5. Aerial methods in forest surveys in B.C.

Aerial photographs have been made of large areas of Canada (6). When administration of the Railway Belt was returned to the Provinces, the British Columbia Forest Surveys Division commenced an economic forest survey of certain areas previously gazetted as National Forests. Portions of this area, in particular the Niskonlith, Shuswap, Fly Hills and Larch Hills Forests had been photographed in 1928 and 1930 for the Topographic Survey of Canada, and it was decided to utilize this photography in connection with the forest survey.

The nature and purpose of the work of the B.C. Forest Surveys Division has been described by F. D. Mulholland, the problem of utilizing aerial photography to advantage in these projects will be better understood on perusal of Mr. Mulholland's article (7).

The problem confronting the forester is twofold. First, to identify and delineate forest types on the photographs; second, to incorporate this information on a map, preferably before going out in the field.

Part I of this discussion deals with the photogrammetric problems as such, while Part II will treat of the methods of identifying and evaluating forest types from the photographs. 


\section{Fundamental Properties of Vertical Photographs}

\section{Scale.}

Vertical aerial photographs are obtained when the optical axis of the camera points vertically downwards. In figure $1, \mathrm{a}$ and $\mathrm{p}$ are the image positions of the points $A$ and $P$ on the plane $G$. The camera lens is at $\mathrm{L}$ and $\mathrm{pLP}$ is the optical axis. The picture plane $\mathrm{paa}^{1}$ is normal to the optical axis, which latter is by definition of course vertical. The scale of the photograph may be represented by the ratio of the distance ap on the photograph to the same distance on the ground.

From similar triangles,

$$
\text { Scale } s=a p / A P=p L / L P=f / H
$$

Thus if the country were flat the scale would be constant over the whole area of the picture, and equal to $f / H$.

If, however, the point $A$ is at some higher elevation $A^{1}$, the scale is no longer $f / H$ but $f / H^{1}$. $a a^{1}$ is the displacement of a from its position due to the elevation difference $\mathrm{e}$.

The magnitude of $\mathrm{aa}^{1}$ may be considerable. Where $\mathrm{H}$ is $10,000^{\prime}, \mathrm{e} 2,000^{\prime}$, and AP 4,000', with a lens of $12^{\prime \prime}$ focal length we have:

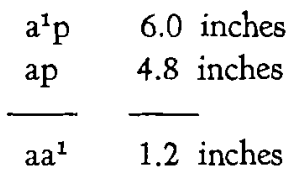

Further by differentiating equation (1) with respect to $\mathrm{H}$ we obtain

$$
\mathrm{ds} / \mathrm{dH}=-\mathrm{f} / \mathrm{H}^{2} \text {. . . . (2) }
$$

That is to say the ratio of the change in the scale to the change in height varies inversely as the square of the height, increasing as the height decreases. This relation is of practical significance as will be explained later. A well known example of the working of this law is seen in the product of some amateur photographers who attempt to take a close-up of a person reclining on the ground, his feet towards the camera. The feet will occupy a far more prominent position than the eye is used to seeing.

Unfortunately for the forester, at any rate in British Columbia, flat country is seldom forest land, so that one must definitely give up all idea that a vertical aerial photograph gives a reduced uniform scale image of the country it represents. However, this difficulty, which may at first sight ap. pear formidable, gives little trouble in practice.

2. Properties of $p$.

Figure 2 is a plan view of figure one, containing in addition the point $\mathrm{B}$ not shown in the first illustration.

The rectangle $r$ represents the negative. The lens $L$ is at a distance $f$ 
vertically below $\mathrm{p}$. The line $\mathrm{A}^{1} \mathrm{La}^{1}$ intersects the plane of the picture in $\mathrm{a}^{1}$, and the line $A L a$, in a. Since $A^{1}$ is vertically above $A$, these points coincide in plan, as do $B$ and $B^{1}$, as well as $P, L$ and $p$. Since $A A^{1}$ and $P$, and their projections, are in the same vertical plane, which plane is shown hatched in figure one, it is evident that $a a^{1}$ and $p$ are on the same straight line. That is, the elevation displacement is radial from p. Once this really simple fundamental property of a vertical photograph is definitely grasped, no difficulty will be experienced in the use of the photographs.

An important corollory follows. The angle $\mathrm{a}^{1} \mathrm{pb}^{1}$ on the picture is equal to the angle APB on the ground. A vertical photograph is "angle true" with respect to the point $\mathrm{p}$.

3. Recapitulation.

The following are the salient properties of vertical aerial photographs:

1. With the single exception of a flat area, the scale of a photograph is not constant but may vary widely from point to point.

2. The true position in plan, on any scale, of a point on the picture is on the line or line produced joining its image position with the point $\mathrm{p}$. Its displacement is towards or away from $\mathrm{p}$ according as the point is lower or higher than $\mathrm{p}$.

3. The angle at $p$ subtended by any two points on the photograph is the same as that which would be measured on the ground from the point vertically below $\mathrm{p}$.

4. Optical and Geometric Considerations.

In the foregoing discussion the following assumptions have tacitly been made, using the notation of figure 1 :

1. That $\mathrm{pL}$ is the focal length of the camera.

2. That PLp is normal to the plane of the photograph.

3. That a ray of light from $A$ passes in a straight line from $A$ through $L$ to $\mathrm{a}$.

A complete discussion of these points is contained in the reference given (8-pp 10 and 79). It will be sufficient to state here that no error commensurate with the system of plotting hereinafter described will be introduced by considering these assumptions rigidly true.

5. Tilt.

The point $p$, to which reference has frequently been made is known as the principle point of the photograph. This may be defined as follows:

"The foot of the perpendicular from the internal perspective centre to the plane of the photograph is known as the principal point." (8-p. 11)

This point is accurately located during the calibration of the camera, and 
etched on the glass focal-plane plate, it consequently appears on each print as a small black cross in the centre of the field.

So far the discussion has been confined to the case of an untilted photograph, i.e., one in which the line PLp of figure 1, is vertical. The point on the ground vertically below the centre of the lens is called the ground plumb point, and its image on the picture plane, the photo plumb point. In an untilted photograph the photo plumb point coincides with the principal point, $\mathrm{p}$. With a tilt of $3^{\circ}$, the displacement of the photo plumb point from $\mathrm{p}$ will be about $6 / 10$ of an inch. (For $\mathrm{H}-10,000^{\prime}$ and a $12^{\prime \prime}$ focal length). Tilt in excess of this amount is rarely encountered.

In the radial line method of plotting a simple construction is available for adjusting this, and so long as tilt of constant magnitude does not occur in successive photographs, it is still possible to make a sufficiently accurate plot.

\section{The Principal Point Plot.}

1. Overlap.

In order that bearings may be carried from one photograph to another, each photograph of a flight must contain the principal point of the preceding and of the following picture. This requirement results in a minimum fore and aft overlap of $50 \%$. To allow for accidental tilts and minor variations in the elevation of the ground it is usual to expose on a fore and aft overlap of $60 \%$ (8). In very hilly country a time setting of the camera to give this overlap for the higher areas will result in a much greater overlap in the low lying country. For example, flights commencing over Adams Lake and covering the mountainous inland areas encounter an elevation range of from 1,340' at the lake to over $6,000^{\prime}$, thus for a plane flying at an altitude of $14,000^{\prime}$, $\mathrm{H}$, the height above the ground, will vary from $12,260^{\prime}$ to less than $8,000^{\prime}$. If the time interval is set so that the distance on the photograph between successive principal points is $3^{\prime \prime}$ when over the mountains, this distance will reduce to 2" near the lake shore. Where, however, more than the three principal points occur on one photograph, as would be the case here, intermediate ones should be discarded, both for the purposes of the principal point plot, and the stereoscopic examination of the area.

Only sufficient lateral overlap is necessary to prevent gaps in the area covered. To allow for accidental departures of the plane from its course, and for minor variations in the ground level, $25 \%$ lateral overlap is usual (8). The lateral spacing of flights, if calculated for the higher areas, will result in an unnecessarily great lateral overlap for the same reasons as explained above. Superfluous views could of course, be discarded, but more efficient coverage may sometimes be obtained by spacing the flights laterally according to a lower elevation, and subsequently flying the gaps. 


\section{Crab.}

In the same way that the actual path of a boat crossing a river is not along the course being steered, but is in the direction of the resultant of the relative motions of the vessel and of the water, so an aeroplane flying through air which may be in violent motion, travels a path with reference to the ground along the resultant of its air speed and the wind velocity. The angle between the true direction of motion and the course being steered is the angle of drift. When the camera is so placed that the edges of the photograph are parallel to the centre line of the plane, then the line of flight on the pictures, obtained by joining the image positions of two successive principal points on the same picture, will be in a diagonal direction with reference to the edges of the view, making an angle therewith equal to the angle of drift, with consequent reduction of overlap. This phenomenon is known as crab. Crabbing is overcome by rotating the camera in azimuth through an angle equal to the angle of drift. The wind velocity is not necessarily cone stant throughout a flight, so that the angle of drift may change, consequently a small and variable crab will usually be present.

3. The radial line method.

Figure 3 is a principal point, or minor control, plot made by the radial line method. It has been shown that an untilted vertical is angle true with respect to its principal point, and this principle is the basis of the radial line method, originated by Major James W. Bagley, U.S.A.

$p$ is optically marked on each photograph as has been explained. On photograph 1 the point $\mathrm{p}^{2}$ is identified, and the points $\mathrm{a}^{1}$ and $\mathrm{b}^{1}$ are chosen. For the geometrically strongest figure $\mathrm{a}^{1} \mathrm{p}^{1}$ should be equal to $\mathrm{p}^{1} \mathrm{p}^{2}$, and $\mathrm{a}^{1} \mathrm{p}^{1}$ at right angles to $\mathrm{p}^{1} \mathrm{p}^{2}$. Where the flight is not straight, as at 2 , a and $b$ should be chosen so as to give as nearly as possible right angled intersections. The points $\mathrm{a}^{3}$ and $\mathrm{b}^{3}$ are not well chosen. Points such as a and $b$ are located on each photograph, and their positions together with those of the principal points are transferred to the preceding and following photographs. The method of transference will be discussed later. For the present let it be assumed that these points are located on well defined features which may be unmistakably identified on each photograph. It will further simplify the argument to assume that $\mathrm{a}^{1}$ and $\mathrm{b}^{1}$ of photograph 1 are at the same elevation, such as on the shore of a lake, or of the sea.

Since $\mathrm{a}^{1}$ and $\mathrm{b}^{1}$ are on the same horizontal plane, equivalent to the plane $\mathrm{G}$ of figure $1, \mathrm{a}^{1}, \mathrm{p}^{1}$ and $\mathrm{b}^{1}$ appear on the photograph in their correct relative positions, to some definite, but as yet undetermined, scale. We further know that $\mathrm{p}^{2}, \mathrm{a}^{2}$ and $\mathrm{b}^{2}$ lie on the lines joining their positions on 1 with $\mathrm{p}^{1}$. This information is all contained on picture 1. The plot is made on thin transparent tracing paper placed over the photograph. $\mathrm{p}^{1} \mathrm{a}^{1}$ and $\mathrm{p}^{1} \mathrm{~b}^{1}$ may 
now be drawn, the trace being placed on picture 1 , together with $\mathrm{p}^{1} \mathrm{a}^{2}, \mathrm{p}^{1} \mathrm{p}^{2}$ and $\mathrm{p}^{\mathrm{l}} \mathrm{b}^{2}$.

Placing the trace now on photograph 2 , the line $\mathrm{p}^{1} \mathrm{p}^{2}$ on the trace coinciding with $\mathrm{p}^{2} \mathrm{p}^{1}$ of picture 2 , the trace is moved, still maintaining this coincidence until the ray $\mathrm{p}^{2} \mathrm{a}^{1}$ on the picture passes through the plotted posi. tion of $a^{1}$ on the trace, thus locating $p^{2}$ on the trace. Since $a^{1}$ and $b^{1}$ are on the same horizontal plane, the ray $\mathrm{p}^{2} \mathrm{~b}^{1}$ will pass through $\mathrm{b}^{1}$ on the trace, if there is no tilt in either picture. In the same way $\mathrm{a}^{2}$ and $\mathrm{b}^{2}$ may now be located on the trace by the intersection of $\mathrm{p}^{2} \mathrm{a}^{2}$ and $\mathrm{p}^{2} \mathrm{~b}^{2}$ on the picture with the rays $\mathrm{p}^{1} \mathrm{a}^{2}$ and $\mathrm{p}^{1} \mathrm{~b}^{2}$ previously drawn. This procedure is repeated with photograph 3 , and so on until the plot is complete.

\section{Adjustment.}

The object of carrying two minor control points, $a$ and $b$, on the plot is to show the existence of tilt, or of accumulated errors of plotting.

When the rays through $\mathrm{a}^{\mathrm{n}-1}$ and $\mathrm{b}^{\mathrm{n}-1}$ on picture $\mathrm{n}$ do not both pass through the previously located positions of these points on the trace this may be due to tilt, to errors of point transference or to accumulated errors in plotting. Before applying the adjustment to be described it is important to check the transference of the points involved, namely $\mathrm{a}^{4}$ and $\mathrm{b}^{4}$ on 3 and 5 , and $\mathrm{p}^{t}$ on 5 for the condition illustrated at 5 in figure 3 . Next check the plotting to assure that no blunder has been made. Large triangles should immediately be suspected. For example a two-inch triangle was found to have been caused by the spotting of a minor control point on a small well defined object which, upon closer examination, was found to be a cloud, the cloud had of course moved during the interval between exposures. A mistake of this nature could not have been made had the stereoscope been used.

Having made certain that the discrepancy is not due to these causes, two positions of $\mathrm{p}$, namely $\mathrm{p}^{\mathrm{a}}$ and $\mathrm{p}^{\mathrm{b}}$ could be obtained according to the ray $p^{5} a^{4}$ on the picture passes through $a^{4}$ on the trace, or $p^{5} b^{4}$ thorugh $b^{4}$. The adjusted position of $\mathrm{p}^{5}$ is within the small central triangle, its distance from the sides of the triangle being in proportion to the corresponding displacements of $a, b$, and $p$. This may be done by eye, and the centre of a small triangle is taken without further question. The plot is carried on from the new position of $p^{5}, p^{5}$ on the trace being placed in coincidence with $p^{5}$ of the picture, and the trace oriented along the new direction $\mathrm{p}^{4} \mathrm{p}^{5}$ as shown. It should be noted that picture 4 is not tilted, or triangles would have shown at $\mathrm{a}^{3}$ and $\mathrm{b}^{3}$.

5. Scale of the minor control plot.

The plot as so far constructed gives the correct relative positions of the principal and minor control points of each photograph of the flight. The scale of the plot could be determined from the equation $s=f / H$. This method 
is sometimes adopted for rough qualitative maps of restricted areas. The only necessary ground control is the elevation of the lake on whose shore $\mathrm{a}^{1}$ and $\mathrm{b}^{1}$ are situated. This, and the altitude of the plane, determines $\mathrm{H}$. Knowing $f$ the scale of the plot may be calculated. The nominal focal length of the lens of the camera used and the approximate altitude of the plane will be found marked on the first picture of the flight. For better results the value of $\mathrm{H}$ obtained from corrected altimeter readings throughout the flight, and the actual value of $f$ as determined in the camera calibration, may be used.

The ordinary method is to locate at least two surveyed points on the plot. The ratio of the distance on the plot to the known distance on the ground will be the required scale. The problem is discussed in section VI., articles 1 and 2 .

\section{Simple Stereocomparison.}

\section{Stereoscopic Impression.}

Stereoscopic impression is the function by which relative distances are subconsciously gauged in binocular vision (3). The angle between rays of light from an object and subtended by the eye base is known as parallax. Thus the parallax of a distant object approaches zero. The smallest angle that can ordinarily be perceived by the human eye is of the order of 30 ". With an object some 20 chains distant the eye base of an ordinary person, about $21 / 2$ inches, subtends an angle of this magnitude. The impression of distances greater than this is therefore not binocular, it depends in fact upon visual angles, or the comparison of known (or estimated) dimensions with apparent dimensions. It will thus be seen that a person with the sight of orly one eye suffers no disadvantage with respect to the estimation of great distances, but may be subject to large errors in his location of nearby objects.

Imagine the left eye to occupy the position of the aeroplane camera when taking the photograph $\mathrm{n}$, while the right eye at the same time occupies the position $\mathrm{n}-1$. The two eyes are supposed still to have their ordinary physiological connection with whatever it is that enables us to enjoy the sensation of sight. Under these conditions it is evident that a binocular impression of relief of the distant ground below would be obtained, since this larger eye base would now subtend angles which the eyes are able to resolve. The stereoscope is an instrument which, by means of a simple optical arrangement, enables this condition to be reconstructed on a reduced scale using the photographs.

2. The use of the stereoscope.

The stereoscope used in the operations to be described consists of a pair of parallel mirrors placed in front of each eye in such a manner that coincident virtual images are formed of each of the photographs being examined, thus giving rise to the illusion of relief. In first examining a pair of photos 
in the stereoscope some difficulty may be found in obtaining the desired relief impression, in particular by those with weak or defective vision of one eye. The following procedure should be observed in placing the photographs to be examined in the stereoscope.

1. The photographs must be in their correct relative position. In one corner of each R.C.A.F. air photo will be found a small arrow giving the direction of motion of the plane relative to the picture. This arrow is etched on the camera focal-piane glass plate, and thus will show on the negative and on each priirt. The photos must be placed so that these arrows point in the same direction, and if the arrow of photograph $n$ points to the right, photograph $n$ plus 1 must be to the right of photograph $n$. This procedure is of some importance for, if wrongly placed, a pseudoscopic relief impression may be obtained, in which mountains are hollows, and creeks flow uphill along sharp ridges.

2. The photographs being placed on the baseboard of the instrument, the direction $\mathrm{p}^{1} \mathrm{p}^{2}$ on print 1 must coincide with the dircction $\mathrm{p}^{2} \mathrm{p}^{2}$ on 2 . A transparent straight edge laid on top of the photographs will enable this adjustment to be rapidly made. Now, looking through the stereoscope, two images will probably be seen. Alter the separation of the photographs, still maintaining the alignment, until these two images blend into one, when the impression of relief shouid be obtained. Look through the mirrors, not at then.

3. The third requirement is that the illumination on the photographs, while examining them in the stereoscope, should be from the same direction as the sun was shining on the ground when the pictures were taken. The rule of thumb is, keep the shadows towards you - the lamps being in front of the stereoscope.

Operation two above has been described as though the principal points had already been transferred. When this has not been done, as when the stereoscope is to be used in the transference of these points themselves, approximate alignment is obtained by observing similar detail of each picture under a transparent straight edge. Accurate coincidence is obtained by rotating each picture about its principal point while the separation is being altered. These operations may be performed very quickly with practice, but it is not advisable to dispense with the use of the straight edge until facility has been acquired in the use of the instrument.

There are some people who have not the stereoscopic ability. A simple way of finding out is to ask the observer to sketch in the form lines, for of ten shadow and light effects, together with "common sense" make a novice believe he is getting the effect when in reality he is not. Once obtained, however, it is unmistakable. The description given if read in conjunction 


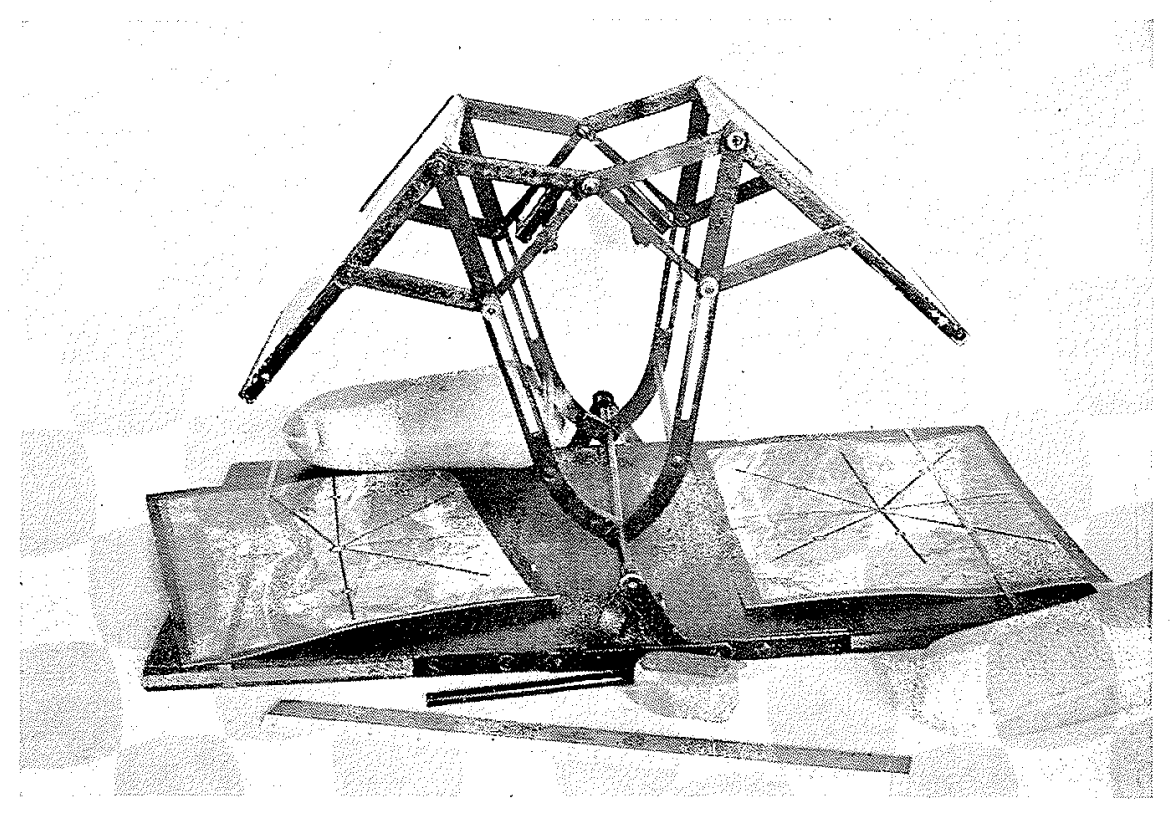

Simple mirror stereoscope which may be used to carry out the operations describer in section IV. A precision topographic sterenscope with grid plates possesses many advantages over tlie instrument illustrated which is only suitable for conparatively rough qualitative work.

with the examination of actual photographs in a stereoscope, should enable the operation to be readily carried out.

3. Floating marks.

Figure 4 represents diagrammatically the examination of the photographs $n^{1}$ and $n^{2}$, a virtual image of the object $A$ being formed in the piane $G$. If a transparent mark such as an "L" etched on a piece of thin celluloid, be laid on each photograph at $\mathrm{a}^{1}$ and $\mathrm{m}^{1}$, a fused image $\mathrm{m}$ in the shape of a cross will be formed on the plane $G^{1}$. $m$ will appear to "float" in space over the relief image-for this reason such marks are known as floating marks. When $\mathrm{m}^{1}$ is moved to $\mathrm{a}^{2}$, the image of the point $A$ on $\mathrm{n}^{2}$, the fused mark $m$ will appear to lie on the ground at A.

In precision model stereoscopes these marks are placed in focal planes of the eyepieces of the binocular telescopes or microscopes, and the change in separation $\mathrm{m}^{1} \mathrm{a}^{2}$ may be measured, and consequently the depth $\mathrm{GG}^{\prime}$ determined.

The marks illustrated in figure $4 \mathrm{~A}$-which is drawn about full size-are the shape recommended for general use. The lines may be scribed on pieces of thin celluloid, and the scratches filled with ink. A better plan is to 
scribe suitable marks on undeveloped or fogged film, printing them on an ordinary new film.

4. Transference of points.

To use the marks to transfer the point $\mathrm{a}^{1}$--which may, for example, be the principal point of $n^{1}-$ from $n^{1}$ to $n^{2}$, the photographs being properly set in the stereoscope, place one of the marks accurately over $\mathrm{a}^{1}$, and the other approximately at $\mathrm{a}^{2}$ on $\mathrm{n}^{2}$. Looking through the stereoscope fuse the two marks, which will now appear to float in space over the relief model below. Alter the position of the second mark until the cross appears to lie on the ground exactly at $A$. The point is located by pricking through the celluloid with a fine needle.

In using this method of transferring points it is essential that the stereo. scopic impression be retained throughout the operation, and that the mark does actually seem to tloat. If a good relief effect cannot be obtained, or for the transference of points on water, another method must be used.

5. Points on water.

When there is no tilt, any point on the surface of a lake is angle true with respect to any point on the shore. Consequently when a point falls on a water surface, it may be located by angular measurement from two or three shore points. As $\mathrm{H}$ will not change appreciably from one exposure to the next, the scale of the lake will be virtually the same in each photograph so that the point could also be transferred by measurements of distance.

6. Transference by eye.

Points may often be transferred by eye, and though no large error is likely, the method is not in general precise and should be used sparingly at first, particularly in long flights where the rapid accumulation of these small errors may lead to a seriously inaccurate plot. A topographic feature may appear quite different from the different points of view of the three successive photographs. Each point must be located on three pictures, and the plane will have travelled about a mile during this time, while the object will appear to have moved across the width of the photographs. The top of a cliff may be mistaken for its shadow, the corner of a barn for the gable, and so on. The intersections of roads and of creeks, the corner of a field and points of a like nature may, however, be rapidly and accurately transferred by eye.

\section{Simple Mapping from Stereoscopic Pairs}

\section{Preparation of the Prints.}

In the making of the principal point plot, it will be remembered that the relative positions of the principal and minor control points have been located in plan on the scale of the plot. The positions of the minor control points 
have been chosen with regard to the geometric strength of the figure rather than on features it is desired to map. They provide however a network of nine points on each photograph, and this will often be sufficient to locate the required detail. When necessary other points may be established by intersection.

Detail to appear on the trace is outlined on the photographs so that it may be seen through the tracing cloth. Coloured wax pencils readily mark the surface of the print and the use of two or more colours will avoid confusion in the transference of detail from the photographs to the plot.

This outlining is largely done in the stereoscope, particularly in the case of smaller watercourses and forest types. Rivers, lakes, roads and any other features clearly delineated on the pictures may be outlined without the use of the stereoscope.

Owing to the overlap, detail to be mapped will, of course, appear on two photographs. The outlining is done only in the overlap portions of each photo. Thus on picture 5 outline between $p^{5}$ and $p^{6}$ only, on 6 between $\mathrm{p}^{6}$ and $\mathrm{p}^{7}$, and so on. This not only avoids duplication of work but has the advantage of leaving available for inspection photographic detail covered by the crayon on the adjacent print.

2. Transference of detail to the plot.

It has been shown (II. 1) that not only is the scale of each photograph usually different, but also that there may be large variations of scale within individual photographs. For these reasons detail on the photographs cannot be transferred by tracing. It has been shown (II. 2) that the true position in plan, on any scale, of a point on the picture is on the line or line produced joining its image position with the principal point of the photograph.

Figure 5 shows the general principle applied to the shore of a lake. The trace is placed on the picture, $p$ of the trace coinciding with $p$ of the picture. The rays from $p$ on the trace orient along those of the photograph. $A^{1} B^{1}$ $\mathrm{C}^{1}$ is the image position of the lake shore. $\mathrm{A}^{1}$ has been chosen as a minor control point, so that $A$ is located. Any other point, such as $B$, must lie on the line joining its image position, $\mathrm{B}^{1}$, with $\mathrm{p} . \mathrm{A}$ and $\mathrm{B}$ are at the same elevation, hence $A^{1} p / A P=B^{1} p / B p$. That is to say $A B$ is parallel to $A^{1} B^{1}$. As many points as may be required are established in this manner.

Figure 6 illustrates a condition where there is a considerable difference in elevation between the points. Note that $\mathrm{A}$ is much higher than $\mathrm{C}$, since $A^{1} p / A p$ greatly exceeds $C_{p}^{2} / C_{p}$ (see figure 1 ) $A$ and $C$ have been intersected on the trace. $\mathrm{X}^{1}$ is the image position of a point in the same straight line as $\mathrm{A}$ and $\mathrm{C}$, its position on the trace is at $\mathrm{X}$. Since $\mathrm{B}^{1}$ is not in the same straight line as $\mathrm{A}$ and $\mathrm{C}$, its position may be located so that $\mathrm{BX} / \mathrm{Bp}=$ $\mathrm{B}^{1} \mathrm{X}^{1} / \mathrm{B}^{1} \mathrm{p}$. The assumption made is that $\mathrm{B}$ and $\mathrm{X}$ are at the same elevation. 
Where $\mathrm{X}$ is known to be at a different elevation than is $\mathrm{B}$, the position of $\mathrm{B}$ may be adjusted accordingly.

In figure $7, A^{1}$ and $B^{1}$ are intersected points whose positions on the trace are $A$ and $B$. If $A$ and $X$ are at the same elevation, $A^{1} X^{1} / A^{1} p=A X / A p$. If the creek is in a steep draw, $A$ will be higher than $X$, exaggerating the distance $\mathrm{A}^{1} \mathrm{X}^{1}$ on the picture, (compare this with figure 1), in which case further adjustment must be made, placing $X$ closer to $A$. Note how the boundaries of $Q$ are located by rays to $p$, as is the irregularity at $r$.

The method given for drawing the shore of a lake is precise, within the limits of graphical plotting and in the absence of tilt. Results obtained from the method of figure 7 will depend upon the skill of the operator. This method should not be used for important features in rough country. Minor control points may be chosen on points such as $\mathrm{X}$ and $\mathrm{Y}$ if it is possible to do so without weakening the plot. It must be remembered that upon the strength of the principal point plot depends the accuracy of the photo-gram. metry. Time will not be gained by weakening the plot in order to save a few additional intersections. This applies in particular to long flights with little ground control.

It has been shown (II., 1) that the rate of change of scale varies inversely as the square of $\mathrm{H}$, the scale increasing as $\mathrm{H}$ decreases. This relation is illustrated in figure 6A. Gound points 1 to 12 are equally spaced on a steep sidehill, their positions on the picture plane are $1^{\prime}, 2^{\prime}, 3^{\prime}$, etc. The spacing of these image positions is in accordance with the formula of equation (2). $1^{\prime}-2^{\prime}$ on the picture, though much smaller than $10^{\prime}-11^{\prime}$, represents the same distance on the ground. $12^{\prime}$ is outside the field of the camera.

The average local scale betwen $8^{\prime}$ and $9^{\prime}$ is $\mathrm{d}^{1} / \mathrm{D}$. The principal point plot is supposed to have been drawn on a scale corresponding to 6 . The scale of the plot is $d / D$. The line $I^{1} \mathrm{~L}$ is a ray from an infinitely distant point on the plane 1-12. $\mathrm{I}^{1}$ will appear on the horizon on the photograph, but cannot of course appear on the plot.

In steep country care must be taken in estimating the positions of points, particularly near the edges of the photograph and when exterpolating beyond an intersected point. Figure 6a should be borne in mind when doing this work. When in doubt intersect the point, two rays will do. It takes but a moment and is perhaps the best way to understand the process. Surprisingly accurate results may be obtained by estimation after a little practice.

In general two adjustments will be necessary. The first as the scale of the plot will not usually be that of the particular photograph on which you are drawing, the second to allow for variation due to local differences in elevation. These are treated separately in the explanation of figure 7 . In order that this first adjustinent may be small the scale of the plot should not 
differ greatly from that of the photographs. See also Section VII., 4, para. 7.

This method of "equating" detail in conjunction with the radial line method of plotting is applicable to scales of the order of 1:30000 with ground control at about ten-mile intervals in each flight.

3. Topography.

One of the most important applications of aerial photography is in the preparation of a topographic map. Most of the photography to date in Can-

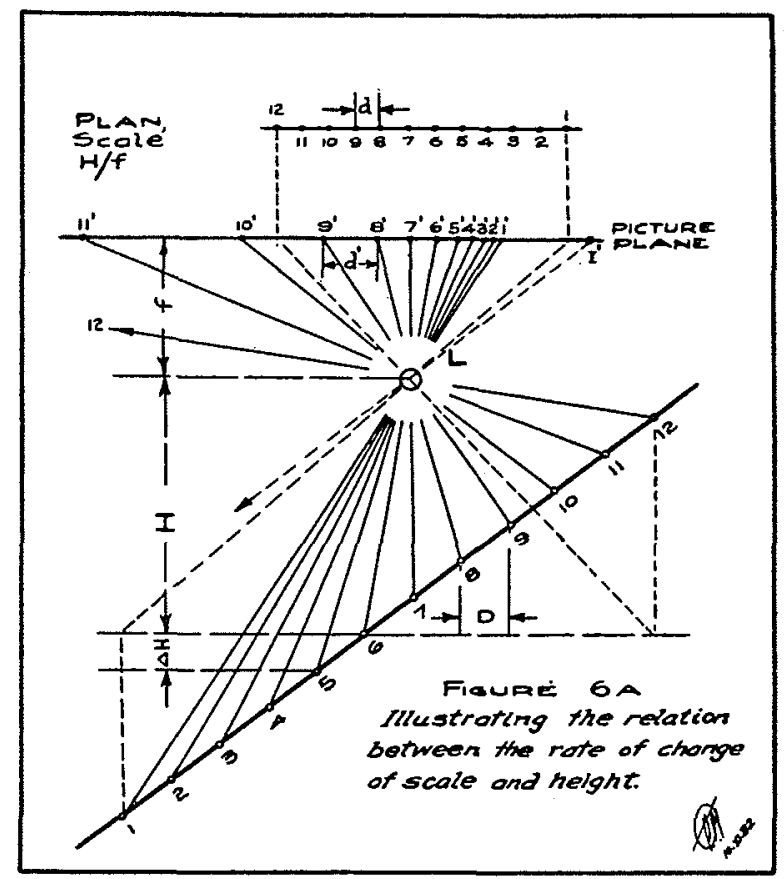

ada has been taken for the Topographic Survey and maps are available or are in the course of preparation covering these areas. A brief outline of a general method follows. Referring again to figure 1, it is seen that the displacement $\mathrm{aa}^{1}$ results from the difference in elevation e. Hence $e$ may be determined from measurement of $\mathrm{aa}^{1}$. If $\mathrm{A}^{1}$ be the principal point of the next photograph it will be seen how the elevation above $G$ of each principal point of the flight could be obtained. It should be pointed out that this method is rough, especially working from paper prints, and cannot be relied upon over distances in excess of a few miles between points of known elevation.

Individual spot heights on each photograph may be determined as is sug. gested in IV, 3, (or from the ground control, or from horizontal ground 
photos, or from any combination of these methods) their number being de. pendent upon the topography of the country and the required accuracy of the map. Interpolation of contours between these spot heights is carried out in the stereoscope.

Sterecomparators and automatic plotting machines of various types employ modifications of the parallax principle outlined elsewhere. The Nistri Photocartograph uses a system which, however, is not stereoscopic. By means of twin projectors the perspective conditions are reproduced to the scale desired. The image is projected on a screen in such a way that only points at the same elevation appear distinct. The contour is then transferred to a drawing board by means of a pantagraph mechanism.

Topographic maps of almost any desired degree of accuracy may be pro. duced from aerial photographs. The contour interval may be anywhere from five hundred feet to, with adequate control, (and suitable flying heights) a meter or less. Plans for engineering projects giving spot elevations to a tenth of a meter have been made and used.

\section{The MAP}

\section{Ground Control.}

In the usage being discussed, existing land surveys will generally provide sufficient control for the aerial work, at any rate for the purposes of the preliminary map. The ground party in the field is in a position to check the accuracy of the preliminary air map and can run additional control if necessary.

Survey lines, if not too old, may usually be picked up on the photos. Railways, roads and lakes are easily identified.

It is assumed that a base map has been made incorporating existing sur. veys. The index map gives the approximate location of the flight. It is next necessary to identify on the photographs points on these surveys. After a little experience in reading photographs this is not a very difficult matter. The points so identified are transferred to the minor control plot by intersection. Where there is a choice of several points, choose the one which may be most definitely established on the plot. Control every few miles is desirable, and should always be incorporated when available.

2. Reduction of minor control plot to scale of base map.

The trace is reduced by pantagraph from the scale on which it was plot. ted to that of the base map. The length of the graduated arm on most pantagraphs is 98 units. The required reduction is determined by measuring the distance between two control points on the base map and on the trace. This ratio times 98 , will give the actual setting of the pantagraph arms. 
Having a number of surveyed points $\mathrm{A}, \mathrm{B}, \mathrm{C}$, etc., transferred to the plot, measure their distances on the base map and on the plot. The scale determined by the ratio of these distances would be the same throughout the length of the plot, were the work accurate. The variation ordinarily obtained in practice is shown in the following example-

Variation in Scale Throughout a Long Plot

\begin{tabular}{|c|c|c|c|c|}
\hline Tie & \multicolumn{2}{|c|}{ Distance, inches } & On base map \\
\cline { 2 - 5 } & scale 2"-1 mile & on m. c. p. & $\begin{array}{c}\text { Reduction } \\
\text { ratio }\end{array}$ & $\begin{array}{c}\text { Pantagraph } \\
\text { setting }\end{array}$ \\
\hline A to B & 15.80 & 40.6 & $2.57: 1$ & 37.36 \\
B to C & 10.88 & 27.1 & $2.49: 1$ & 38.54 \\
C to D & 10.25 & 25.3 & $2.47: 1$ & 38.89 \\
D to E & 9.05 & 22.4 & $2.471 / 2: 1$ & 38.79 \\
\hline
\end{tabular}

Above data is from flight A-528 in the Shuswap Forest. This portion of the flight is 23 miles long.

Each portion $A B, B C$, etc., of the flight is pantagraphed separately using the setting shown.

3. Transference of reduced minor control plots to base map.

After being reduced by pantagraph the distance between ties on the reduced trace will be equal to their distance on the base map, and the plot is transferred thereto using carbon paper and a stylus.

In transferring the adjoining flight, difficulty may be experienced owing to the non-coincidence of detail in the lateral overlap. With adequate ground control, the conflicting features may be blended without much trouble. The reduced minor control plots are pantagraphed on tracing paper so that the overlapped detail may be examined by placing the trace in its proper position on the map, when the position of a feature, as indicated by each flight, is readily apparent.

The first flight transferred should be a good one. That is, it should be adequately controlled and free from tilt, as evidenced by the absence of triangles in the minor control plot.

An intersected point will be given more weight than one merely equated, locations nearer a tie will be stronger than those further away. Figure 8 illustrates these points. The position of the south fork of the creek is taken from the south flight as it passes through the north minor control point of 3 . The forks near $p$ of 14 are probably in their correct position. The lake which 
has been used as a tie for the north flight, is of course correct as shown, moreover the other position is only estimated.

The lake should have been used as a tie for both flights. Its location from the south flight should be checked by rays from 4 and 5 , and if its position does not agree, 4 and 5 should be adjusted, and the detail changed as shown.

These operations will be facilitated by using differently coloured carbon papers in tracing alternate flights, thus the location of a feature, as from two (or more) flights, may be easily identified.

\section{Special Difficulties.}

It may sometimes happen that two adequately controlled flights are separated by several with little or no control. Under these circumstances, it will be necessary to use unsurveyed points located on the common lateral overlap, adopting their position as shown by the controlled flight: The controlled flights are first transferred to the base map, when the distance between the points to be used as control may be determined.

Where the distance between the controlled flights is great, it is likely that, working from the one flight, a considerable discrepancy may be found on reaching the other. It will be advisable first to make a frame-work, consisting only of points used for control. Adjustment of these points to close is made, and the final pantagraph setting determined from these adjusted positions.

The network may be likened to several pairs of lazy tongs laid side by side. The problem is to tie these together, making a strong and rigid structure.

\section{Practice}

1. The Index Map.

As an area is being flown the approximate positions of the principal points of, say every fifth picture, are marked on an existing map of the locality. It will usually be possible to identify ground points on several photographs. The intermediate positions may be plotted from the pilot's notes of his course during that particular flight. The map showing these positions is called the index map.

Most flights run in an easterly or westerly direction. This is due to the behaviour of the magnetic compass. Owing to the effect of the vertical component of the earth's field on the needle, accurate north and south lines cannot be flown with a magnetic compass. 


\section{Filing System.}

Photographs are filed according to their geographic position. Quads one degree by one degree, referred to by their south-east corners, are divided into four. Thus "51-119 N W," means that the flight in question is in the northwest quarter of the quad whose south-east corner is 51 degrees latitude and 119 degrees longitude. The flight sare fled according to their positions as shown on the index map.

Prints of the aerial photographs, both obliques and verticals, are on file at Provincial Government offices and are available for inspection and use. Copies are obtainable from the Department of National Defence, Ottawa.

3. Detailed order of operations.

In mapping any considerable area, the work should be undertaken in a systematic manner. The order of operations given below has been found satisfactory in practice, and while it is not suggested that this procedure is incapable of improvement, it will be advisable to follow it until considerable experience has been gained in the work.

1. Mark and prick principal points.

2. Transfer principal points in the stereoscope.

3. Choose, mark and prick secondary control points.

4. Transfer secondary control points, usually in the stereoscope.

5. Draw in radials on the backs of the photographs.

6. Outline drainage, required detail and forest types.

7. Make principal point plot.

8. Transfer the detail to the plot, making allowance for scale, and local variation in scale.

\section{Explanation of the Operations.}

These operations for the most part have been described, for convenience reference is here given to the sections in which the descriptions occur, together with additional practical information.

1. Using a Blaisdell china-marking pencil place a circle around the small cross marking the principal point of the photo. Should the cross be difficult to find, it may be located by intersecting the diagonals drawn from the $\mathrm{L}$ shaped calibration marks appearing at the corners of the print.

With a fine needle in a suitable holder prick through the centre of the cross and mark the back of the photograph. Caution, keep the pricker vertical. Put the picture number on the back, near the pricked position of the principal point. 
The surface of the photographs may be marked in a variety of ways. Blanc d'argent is often used, this may be erased with a damp cloth, or merely with the moistened finger. Wax or china-marking pencils, obtainable in a variety of colours, are satisfactory. If the print is to be cleaned afterwards, their use is advised. A rag moistened with gasolene will remove all trace of the markings, and the soft wax will not scratch or indent the surface of the print. The emulsion, being insoluble in gasolene, will not be damaged or distorted as may be the case when water is used.

2. See section IV., 3, p. 45 , et seq.

3. See section III., 3, p. 42, and the last paragraph on page 43. Operation 3 cannot be performed properly until after the principal points have been transferred, operations 1 and 3 should not therefore be combined.

4. As for operation 2.

5. Using a sharp $4 \mathrm{H}$ pencil carefully join the pricked position of the principal point, on the back of each photograph, with the adjoining principal and the minor control points. On the lines joining the principal points place arrows to show the direction of flight.

6. Section V, 1, p. 47.

7. Section III, 3, p. 42. The operation is carried out from the backs of the photographs. This does not affect the theory of construction of the plot, and has the advantage of enabling accurate work to be performed from the clean white surface of the reverse of the print, leaving the face free from radial lines which sometimes disturb the stereoscopic impression. On turning the trace upside down the plotted positions of the principal and minor control points, visible through the transparent tracing medium, will appear in the same sense as on the faces of the photographs.

The scale of the plot is fixed as soon as the second principal point is located, and will be the local scale of the first photograph. Where a tlight encounters a considerable elevation range, this scale may be inconvenient over the higher parts. Adjustment should be made so that the scale will be ap. proximately that of the largest number of photographs from which detail is to be transferred. This may be calculated from equation (1) and a knowledge of the approximate elevation. Example: Elevation at picture 1, 1,000 ft. If the altitude of the plane is $15,000 \mathrm{ft} . \mathrm{H}=14,000 \mathrm{ft}$. Let the average elevation of the area to be mapped be $4,000 \mathrm{ft}$. we then require a scale corresponding to $\mathrm{H}=10,000 \mathrm{ft}$. The trace should accordingly be shifted until the distance from $\mathrm{p} 1$ to $\mathrm{p} 2$ on the plot is about $14 / 10$ times this same distance as shown on photograph 1 .

Before commencing the actual principal point plot it is advisable to care- 


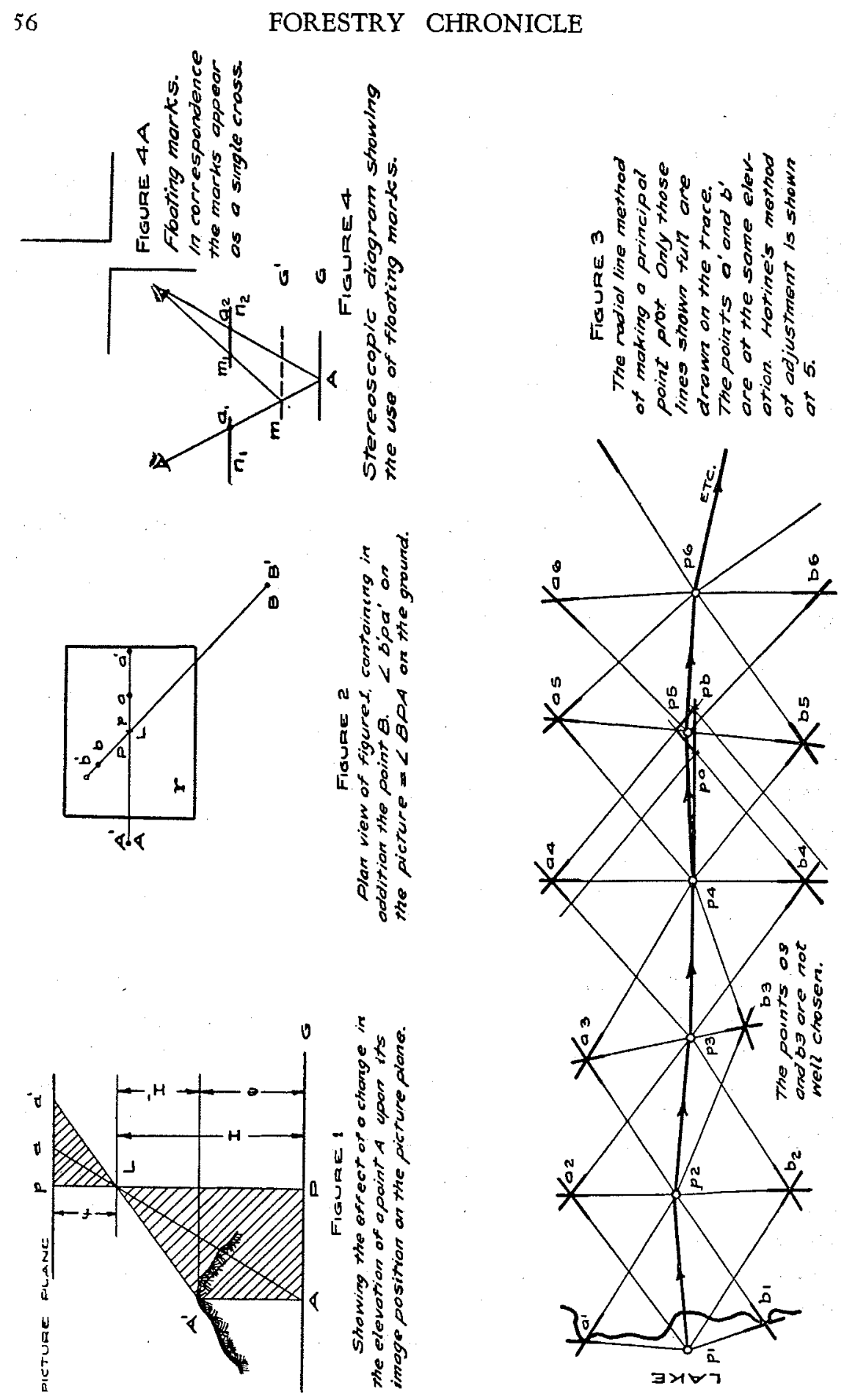



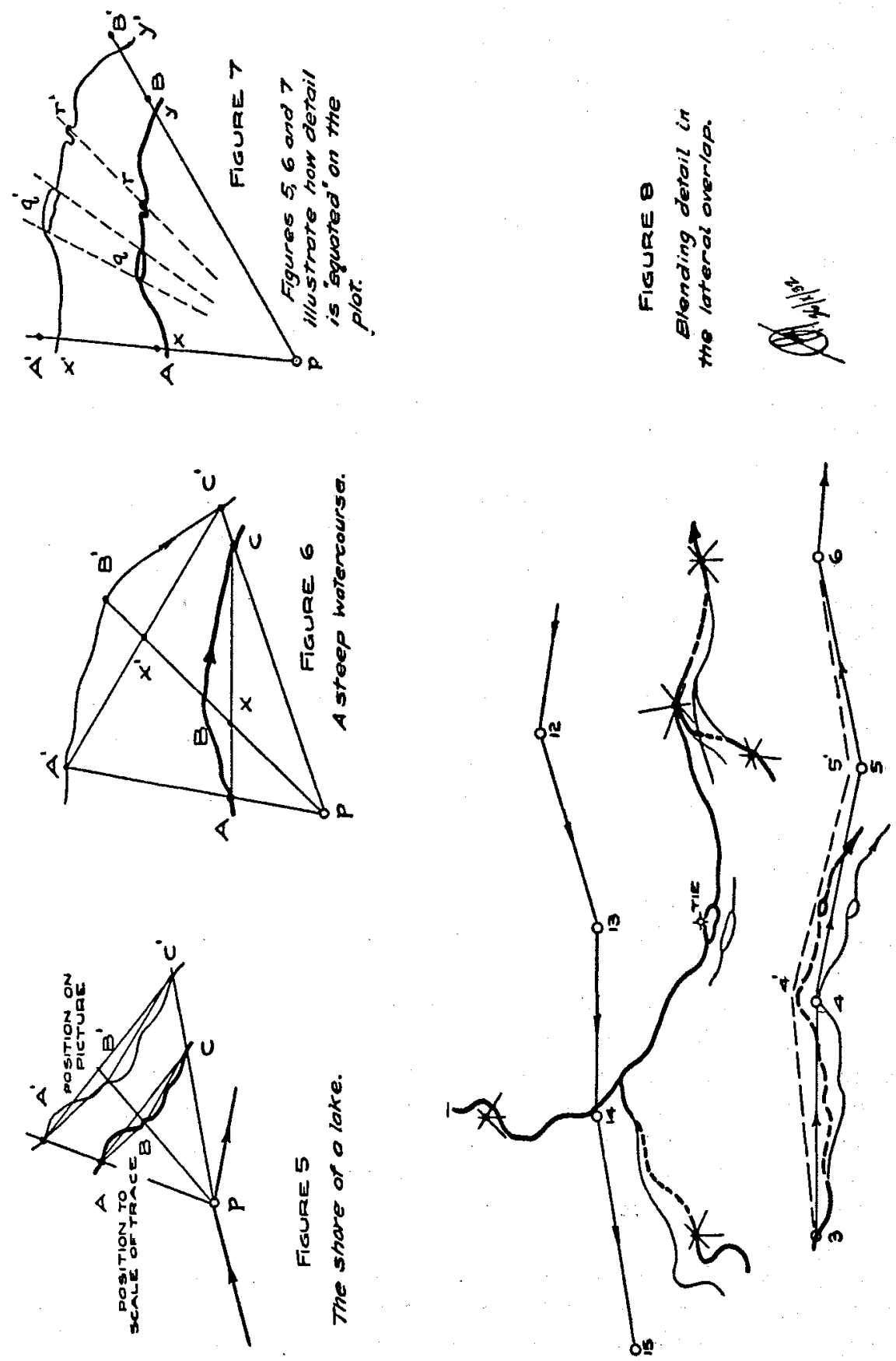
fully lay the photographs out on the floor or on a large table, in order that the first photograph may be so oriented that the plot will not run off the tracing paper. It will also save time and exasperation to arrange the pictures in their proper numerical order, and to keep them so throughout these operations.

8. See section V, 2, p. 48.

At the completion of operation 8 the natural scale principal point plot is ready for reduction and transference to the base map.

5. Organization.

In a large project comparatively unskilled men may perform certain of these operations, while others require a different degree of skill or technical training. In the particular case of a forest cover map, the delineation and identification of forest types on the photographs will, for example, require the employment of a forester with experience and training in this work. The largely mechanical operations of point transference may be taught any intelligent man in a few hours, provided that he is physiologically able to acquire the necessary stereoscopic ability. The making of a usable principal point plot more than five or six miles long requires a really high order of workmanship. The blending of a number of plots into an accurate and coherent whole is perhaps as much an art as a science, rapidly increasing in complexity as the amount of ground control decreases. Experience in plane table and similar work is a decided advantage in this respect, and should be supplemented by an understanding of the iconometric problems involved, together with a knowledge of the principles of balancing and weighting.

6. Accuracy.

The methods described are, in the first place, limited in accuracy to that attainable by any graphic system, and have the further disadvantage that the errors accumulate rapidly with an increase in the distance between ties. This is why it is necessary to exercise great care in the construction of a long plot.

The absolute position of any one intersected point will, in general, be located with the same order of accuracy as by plane table methods. The important characteristic of the air map will be the wealth and relative accuracy of the detail. It must be remembered that the resultant accuracy of the photogrammetry is limited by the intensity and accuracy of the ground control, whether the project be a forest reconnaissance, or a railway location requiring elevations to the tenth part of a meter.

7. Costs.

A question of practical importance is how much does mapping of this nature cost. The following table shows results which have been obtained, and will give some idea of the time taken in each operation. 
Time Tests

\begin{tabular}{|l|c|c|}
\hline Operation & $\begin{array}{c}\text { Test I. } \\
\mathrm{f}-10^{\prime \prime} \text { at } 15000^{\prime}\end{array}$ & $\begin{array}{c}\text { Test II. } \\
\mathrm{f}-12^{\prime \prime} \text { at } 15000^{\prime}\end{array}$ \\
\hline Mark and transfer pp's & $1: 00$ & $1: 05$ \\
Mark and transfer mcp's & $2: 15$ & $1: 00$ \\
Draw radials & $1: 20$ & $0: 20$ \\
Minor control plot & $1: 30$ & $1: 05$ \\
Mark detail & $1: 10$ & $1: 00$ \\
Transfer detail to plot & $2: 30$ & $0: 40$ \\
Pantagraph & $2: 00$ & $0: 25$ \\
Transfer plot to map & $0: 50$ & $6 \mathrm{hr} .35$ min. \\
\hline Total Hours & 12 hr. 35 min. & 10 \\
\hline Net Area, sq. miles & 24 & 11 sq. miles \\
\hline Area per 7 hr. day & 13 sq. miles & \\
\hline
\end{tabular}

Note that the speed of the photogrammetry is, other things being equal, inversely proportional to $\mathrm{f}, \mathrm{H}$ being constant.

Suitable personnel may be trained to work at this rate in about a week. Records kept of several hundred square miles indicate that estimates based on eight square miles per man day are very conservative.

\section{BIBLIOGRAPHY}

(These works are referred to in the text by number)

1. 1889 Deville, DR. E., Photographic Surveying.

2. 1922 Report of the James Bay Forest Survey, Ontario Forest Branch.

3. 1926 Higativs, A. L., Photo-topography.

4. 1928 Boukne, R., Aerial Survey in Relation to the Economic Development of New Countries. Oxford Forestry Memoirs No. 9.

5. 1928 Stevfinson, H. I., and A. M. NarRaway, Aircraft in Forestry. Canada, Department of the Interior, Forest Service.

6. 1931 Report on Civil Aviation in 1930, Canada, Department of National Defense.

7. 1931 Molfolland, F. D., Forest Surveys in British Columbia, Forestry Chronicle, Vol. VII.

8. 1931 HоTINE, M., Surveying from Air Photographs.

9. 1932 Topographical Survey Bulletin No. 62. The Use of Aerial Photographs for Mapping. Canada, Department of the Interior.

NOTE: A full bibliography is published for the British Air Survey Committee by H.M. Stationery office, and is available upon application. 